\title{
Formation and Properties of Tantalum Carbonitride from $\mathrm{Ta}_{2} \mathrm{O}_{5}$
}

\author{
Osamu Matsumoto* and Michio SAITo*
}

Tantalum carbide and nitride make a continuous cubic solid solution in the region of smaller than 46 mole \% of TaN under an atmospheric pressure ${ }^{1)}$. At higher content of TaN, the cubic solid solution and hexagonal TaN are coexist. Recently, the cubic modification of TaN at higher pressures and temperatures was found ${ }^{2}$.

The cubic solid solution of $\mathrm{TaC}-\mathrm{TaN}$ was a superconductor. The superconducting transition temperature gradually raised with increasing TaN content. The highest temperature was about $11.3 \mathrm{~K}$ for the solid solution of $38 \mathrm{~mole} \%$ of $\mathrm{TaN}^{3)}$.

The authors have studied the formation of superconducting tantalum and niobium carbides by the carbonidation of respective oxides with graphite by heating in the argon plasma $\operatorname{arc}^{4), 5)}$. They also formed niobium carbonitride from $\mathrm{Nb}_{2} \mathrm{O}_{5}$ by the carbonitriding in an nitrogen-argon mixed plasma $\operatorname{arc}^{6}$.

In this note, the formation of tantalum carbonitride by the method given. in the previous paper $^{6)}$ and some properties of the products will be described.

$\mathrm{Ta}_{2} \mathrm{O}_{5}$ (purity above $99.9 \%$, H.C. Stark, Berlin) and graphite (spectroscopic grade, Tokai Electrode Mfg. Co.) were mixed in the desired molar ratio $\left(\mathrm{C} / \mathrm{Ta}_{2} \mathrm{O}_{5}\right)$. About one gram of the mixture was pressed into a tablet. Purified argon and nitrogen were used as the plasma gas.

The plasma arc furnace is the same as described previously ${ }^{7)}$ :: The heating procedure of the tablet with the nitrogen-argon plasma arc was the same as given in the previous paper ${ }^{6)}$.

* Department of Chemistry; College of Science and Engineering, Aowama Gakuin University (6-16-1, Chitosedai,. Setagaya-ku, Tokyo?
Nitrogen was mixed with argon and the current was decreased to prevent the temperature elevation of the tablet; because tantalum carbonitride decomposes at higher temperatures. The surface temperature of the tablet in the plasma arc was $2100^{\circ} \mathrm{C}$.

As the products obtained by heating in the nitrogen-argon plasma arc were not stoichiometric, these products were heated under nitrogen atmosphere at $1500^{\circ} \mathrm{C}$ for a few hours.

The products were investigated by X-ray diffraction and chemical analysis. The superconducting transition temperature of some products was measured by means of $21 \mathrm{~Hz}$ mutual inductance bridge and a germanium thermometer.

The products obtained by heating of $6.0 \leq$ $\mathrm{C} / \mathrm{Ta}_{2} \mathrm{O}_{5} \leq 6.9$ mixture in the nitrogen-argon mixed plasma arc were $\mathrm{TaC}$ or a mixture of

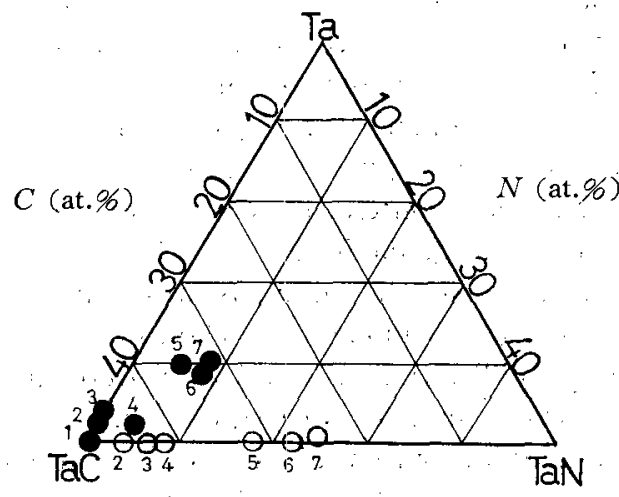

Fig. 1 Composition of products

- Nitriding in the argon-nitrogen plasma arc

$O$ : Nitriding under nitrogen atmosphere at $1500^{\circ} \mathrm{C}$ after nitriding in the plasma arc...

Numbers in this figure represent those in Table 1 : 
Table 1 Chemical analysis data of $\mathrm{TaC}_{\mathbf{x}} \mathrm{N}_{\mathbf{y}}$ after heating under nitrogen atmosphere at $1500^{\circ} \mathrm{C}$

\begin{tabular}{c|c|c|c|c|c}
\hline \hline $\begin{array}{c}\text { Sample } \\
\text { No. }\end{array}$ & ${\mathrm{C} / \mathrm{Ta}_{2} \mathrm{O}_{5}}$ & $\begin{array}{l}\mathrm{Ta} \\
\text { content } \\
\text { (at.\%6) }\end{array}$ & $\begin{array}{l}\mathrm{C} \\
\text { content } \\
\text { (at.\%) }\end{array}$ & $\begin{array}{l}\mathrm{N} \\
\text { content } \\
(\text { at.\%) }\end{array}$ & $\begin{array}{c}\Sigma(\mathrm{Ta}, \\
\mathrm{C,N})\end{array}$ \\
\hline 1 & 7.0 & 50.0 & 50.0 & - & 100.0 \\
2 & 6.9 & 50.7 & 45.7 & 3.80 & 100.3 \\
3 & 6.8 & 50.0 & 43.8 & 6.20 & 100.1 \\
4 & 6.7 & 49.6 & 42.0 & 8.50 & 100.4 \\
5 & 6.3 & 51.7 & 31.2 & 17.1 & 100.6 \\
6 & 6.1 & 50.9 & 28.0 & 21.1 & 100.8 \\
7 & 6.0 & 51.3 & 25.1 & 23.6 & 100.0 \\
\hline
\end{tabular}

Table 2 X-ray diffraction data of $\mathrm{TaC}_{\mathrm{x}} \mathrm{N}_{\mathrm{y}}$ as given in Table 1

\begin{tabular}{c|l|c}
\hline $\begin{array}{c}\text { Sample } \\
\text { No. }\end{array}$ & $\begin{array}{l}\text { Identified } \\
\text { compounds }\end{array}$ & $\begin{array}{c}a \text { of } \mathrm{TaC}_{\mathbf{x}} \mathrm{N}_{\mathrm{y}} \\
(\AA)\end{array}$ \\
\hline 1 & $\mathrm{TaC}$ & 4.455 \\
2 & $\mathrm{TaC}_{\mathrm{x}} \mathrm{N}_{\mathrm{y}}$ & 4.447 \\
3 & $\mathrm{TaC}_{\mathrm{x}} \mathrm{N}_{\mathrm{y}}$ & 4.444 \\
4 & $\mathrm{TaC}_{\mathrm{x}} \mathrm{N}_{\mathrm{y}}$ & 4.442 \\
5 & $\mathrm{TaC}_{\mathrm{x}} \mathrm{N}_{\mathrm{y}}$, & 4.435 \\
6 & $\mathrm{TaC}_{\mathrm{x}} \mathrm{N}_{\mathrm{y}}, \mathrm{TaN}$ & 4.430 \\
7 & $\mathrm{TaC}_{\mathrm{x}} \mathrm{N}_{\mathrm{y}}, \mathrm{TaN}$ & 4.425 \\
\hline
\end{tabular}

$\mathrm{TaC}$ and TaN. These products were tantalum excess compounds as given in Fig. 1. Therefore, it was necessary to add nitrogen into the defect compounds by heating under the nitrogen atmosphere at high temperatures.

The chemical analysis data of the products after heating under the nitrogen atmosphere at $1500^{\circ} \mathrm{C}$ for 8 hours are given in Table 1. Identified compounds and the lattice parameter of a cubic phase are given in Table 2. The Nitrogen content increased by nitriding at $1500^{\circ} \mathrm{C}$ as given in Fig. 1 . Nonmetal to metal ratios in the products after nitriding were nearly stoichiometric. The samples containing smaller than 17 at. $\%$ of $\mathrm{N}$ were single phase which had fcc structure. The samples containing larger than 21 at. \% of $\mathrm{N}$ contained small amounts of hexagonal TaN. The sum of $\mathrm{Ta}, \mathrm{C}$, and $\mathrm{N}$ contents of the products exceeded 100 wt. $\%$. It seems that oxygen content in the products is small in each case. The lattice parameter of the cubic phase gradually decreased with increasing nitrogen content. The density measured picnometrically was nearly equal to the X-ray density.

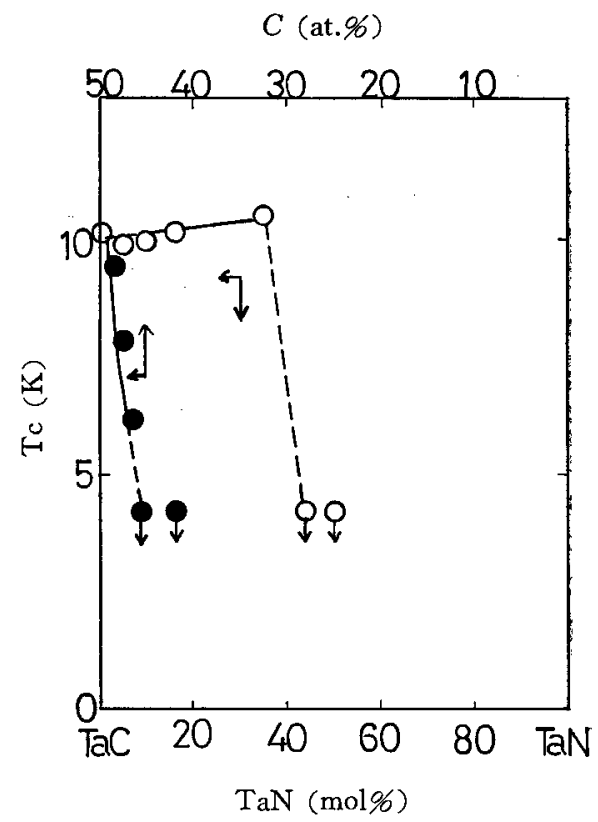

Fig. 2 Superconducting transition temperature vs. composition of $\mathrm{Ta}-$ $\mathrm{C}-\mathrm{N}$ system

-: $\mathrm{TaC}_{1-\mathrm{x}}$ $O: \mathrm{TaC}_{\mathbf{x}} \mathrm{N}_{\mathbf{y}}$

The relation between the superconducting transition temperature (Tc) of the product and the nominal composition of tantalum carbonitride is shown in Fig. 2. Tc gradually rised with increasing nitrogen content. The highest Tc was reached the temperature of $\mathrm{TaC}_{0.62} \mathrm{~N}_{0.32}$ and it was found to be $10.5 \mathrm{~K}$. This tendency is similar that given in the literature ${ }^{3)}$. The samples containing larger than 21 at. $\% \mathrm{~N}$ were normal down to $4.2 \mathrm{~K}$. From Fig. 2 and Table 2, it is clarified that the existence of hexagonal $\mathrm{TaN}$ lowers $\mathrm{Tc}$.

In the region of the cubic phase, Tc of tantalum carbonitride was somewhat higher than that of defective tantalum carbide of the same $\mathrm{C} / \mathrm{Ta}^{5}$. The addition of nitrogen atom to carbon defective carbide rised Tc. This tendency is similar to that given in the case of niobium carbonitride ${ }^{6}$.

If the cubic modification of solid solution of $\mathrm{TaC}-\mathrm{TaN}$ in the region of higher $\mathrm{TaN}$ composition is possible under high pressure and at high temperatures, the superconducting transition temperature will be rise.

$<\mathrm{E} 421>$ (Received May 6, 1975) 


\section{References:}

1) G. Brauer, R. Lesser, Z. Metallk: 50, 512 (1959).

2) L.G. Boiko, S.V. Popova, Zh. Eksp. Teor. Fiz. 12, 101 (1970).

3) L.E. Toth, V.F. Zackay, M. Wells, J. Olson, E.R. Parker, Acta Met. 13, 379 (1965).

4) O. Matsumoto, M. Saito, High Temp. Sci. 6, 135
(1974).

5) O. Matsumoto, M. Saito, Bull. Chem. Soc. Japan 48, 351 (1975).

6) M. Saito, O. Matsumoto, High Temp. Sci. in press.

7) O. Matsumoto, T. Miyazaki, ibid. 5, 40 (1973). 